\title{
6 Beta-Hydroxycortisol Measurement
}

National Cancer Institute

\section{Source}

National Cancer Institute. 6 Beta-Hydroxycortisol Measurement. NCI Thesaurus. Code C150833.

The determination of the amount of 6 beta-hydroxycortisol present in a sample. 